\title{
Yeast as a Rare Cause of Acute Surgical Site Infection Mimicking Necrotizing Fasciitis: A Case Report and Literature Review
}

\author{
Erik Beuker ${ }^{\mathrm{a}}$, Johan Bolton ${ }^{\mathrm{a}}$, Corey Tomlinson ${ }^{\mathrm{a}}$, Shahzeer Karmali ${ }^{\mathrm{a}, \mathrm{b}, \mathrm{c}}$
}

\begin{abstract}
Necrotizing fasciitis following inguinal hernia repair is uncommon. Yeast as the causative agent is reported only once in the literature. Here we present a case of an elective inguinal hernia repair complicated by mesh infection with yeast and necrotizing infection. Yeast as a cause of necrotizing fasciitis after herniorrhaphy is exceptionally rare and an exhaustive literature search uncovered one additional documented case that was ultimately fatal.
\end{abstract}

Keywords: Yeast; Infection; Hernia

\section{Introduction}

Vigilance is emphasized in surgical training as it pertains to surveillance for post-operative wound infections. Prompt diagnosis facilitates optimal patient care but a delayed diagnosis is a source of substantial morbidity and can be lethal. Perhaps the greatest threat from infection comes in the form of necrotizing fasciitis, an acute and rapidly progressive tissue infection requiring aggressive medical and surgical management concurrently. A recently published series demonstrated a $12 \%$ rate of infection following hernia repair [1]. Searching Medline, however, there were no case reports of infectious complications presenting within the first 24 hours following elective herniorrhaphy and pertaining to the diagnosis of necrotizing fasciitis. One fatal case of bacterial necrotizing

\footnotetext{
Manuscript accepted for publication June 12, 2012

${ }^{\mathrm{a} D e p a r t m e n t ~ o f ~ S u r g e r y, ~ U n i v e r s i t y ~ o f ~ A l b e r t a, ~ E d m o n t o n, ~ A l b e r t a, ~}$ Canada

${ }^{\mathrm{b}}$ Center for the Advancement of Minimally Invasive Surgery (CAMIS), Royal Alexandria Hospital, Edmonton, Alberta, Canada

${ }^{\mathrm{c} C}$ Corresponding author: Shahzeer Karmali, Royal Alexandra Hospital, Room 405, Community Services Center, 10240 Kingsway, Edmonton, Alberta, Canada, T5H 3V9. Email: shahzeer@ualberta.ca
}

fasciitis affecting the lower limb presented after perforation of a sliding inguinal hernia only 20 hours post manual reduction. However, this preceded surgical repair [2]. Fortunately, surgical debridement has been successful in other similar cases, although once again preceding any actual hernia repair [3]. One patient undergoing an uncomplicated inguinal hernia repair developed necrotizing fasciitis secondary to bacterial infection but presented on the third post-operative day. This case was ultimately fatal [4].

\section{Case Report}

Our patient is a 41 year-old male who underwent elective open inguinal hernia repair using polypropylene mesh in the standard Lichtenstein fashion. There were no complicating factors; the hernia was not incarcerated and the patient was healthy taking no medications and had no significant past medical or surgical history. At the time of operation the surgeons were presented with a direct hernia along with a small indirect component. The indirect hernia sac was reduced without manipulation or entry into the peritoneum. The direct sac with dissected free of its attachments and reduced without difficulty. Sterile technique was maintained throughout the procedure. The patient was discharged home that same day.

Unfortunately he returned to the emergency room 18 hours later with excruciating right groin pain, swelling and minimal erythema. On physical exam there was evidence of crepitus in the incision, extending into the right flank. Although overlying erythema was minimal, the patient had pain out of proportion to gentle palpation. His vital signs were stable and otherwise normal blood work aside from a mildly elevated white blood count (WBC) of 12 (x 10 $10^{9} \mathrm{~L}$ ). Other signs such as a bronze or bluish discoloration of the skin, blistering of the skin, high fevers or change in mental status were absent [5]. His pain was refractory to injection of $2 \%$ lidocaine in the distribution of the ileoinguinal and ileohypogastric nerves. It should be noted that the laboratory predictors of necrotizing fasciitis such as an elevated WBC count greater than 14 ( $\left.10^{9} / \mathrm{L}\right)$, a serum sodium concentration less than $135 \mathrm{mmol} / \mathrm{L}$ and a urea greater than 15 


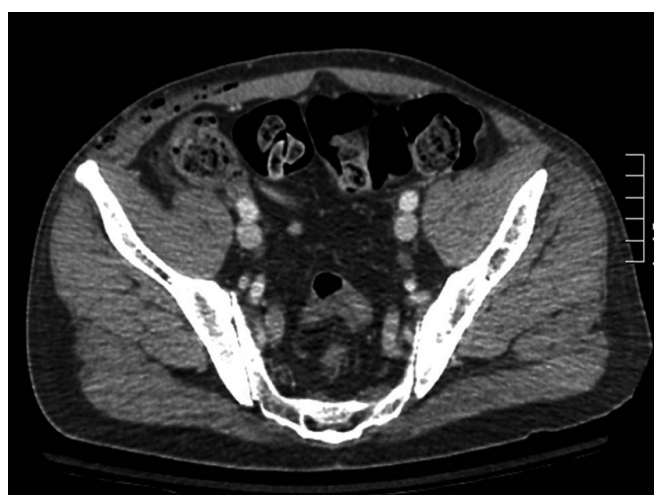

Figure 1. Transverse CT scan of the abdomen demonstrating subcutaneous emphysema to the right flank. Inflammatory changes, fluid, and stranding are noted within the subcutaneous fat.

$\mathrm{mg} / \mathrm{dl}$ were not present [6]. Application of the Laboratory Risk Indicator for Necrotizing Fasciitis (LRINEC) scoring system yielded a low probability for necrotizing soft tissue infection, yet the clinical suspicion in this case was high and broad-spectrum antibiotics were started [7]. With the operating room (OR) immediately unavailable an urgent computed tomography $(\mathrm{CT})$ of the abdomen and pelvis was arranged which demonstrated extensive subcutaneous air and a single concerning locule of air around the cecum (Fig. 1, 2).

The patient was emergently brought to the OR for diagnostic laparoscopy to rule out an intraabdominal source of infection. Intra-abdominal fluid was noted to be turbid. No injury to bowel or bladder was identified, however the appendix was minimally erythematous and was removed. Subsequent pathology demonstrated an essentially normal appendix. The groin was opened through the previous incision and a significant amount of air with of grey, "dish water" discharge was produced, increasing the concern for necrotizing infection. Cultures of both the pelvic fluid and the groin were taken. The mesh was removed and the incision was packed open.

Despite presenting in less than 24 hours, the intra-operative swabs would not demonstrate any aerobic or anaerobic bacterial growth. Surprisingly, the mesh sample would demonstrate the growth of yeast in the 12 hour culture sample. While the pre-operative administration of Piperacillin-Tazocin could theoretically decrease the microbial yield, this would be unlikely to result in negative cultures given the immediacy of reoperation and single dosing. Following the operation, the patient's pain resolved and his WBC count normalized. He was discharged on the $4^{\text {th }}$ post operative day.

\section{Discussion}

A review of the literature reveals that mesh infections in this

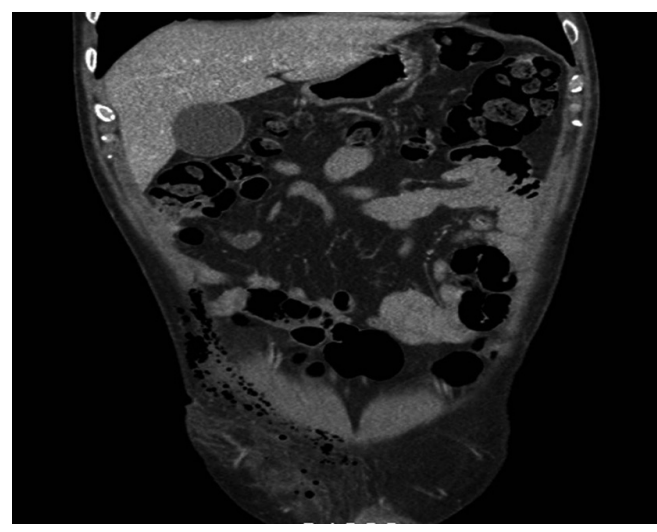

Figure 2. Coronal CT scan of the anterior abdomen demonstrating extensive right inguinal subcutaneous emphysema and inflammatory changes.

clinical context are usually due to intra-operative contamination [8]. The vast majority are bacterial pathogens such as $S$. aureus (including MRSA), Streptococcus spp., E. coli, Enterococcus and Mycobacteria. Atypical pathogens as a cause of necrotizing fasciitis are exceedingly rare and are usually bacterial and have been linked to pathogens like Eikenella corrodens [9]. Recent clinical classification of necrotizing fasciitis has distinguished four types: Type $1(80 \%$, polymicrobial), Type 2 (20\%, generally monomicrobial), Type 3 (gram-negative monomicrobial) and Type 4 (fungal) [10].

Acute mesh infections attributable to yeast or fungi are an extremely rare cause of necrotizing fasciitis (Type 4) following herniorrhaphy as evidenced by a single 1993 case report of zygomycotic fungal infection causing fatal necrotizing soft tissue infection post herniorrhaphy [11].

This report should convey that surgical site infections following herniorrhaphy are infrequent but can carry substantial morbidity and even mortality. Vigilance in identification of post-operative wound infections is paramount and they must remain in the differential of any patient complaining of post-operative incisional pain. Furthermore, the use of risk scoring systems such as LRINEC can aide clinicians in differentiating between high and low risk surgical site infections, but should never supersede sound clinical judgment and physical exam.

\section{References}

1. Nieuwenhuizen J, van Ramshorst GH, ten Brinke JG, de Wit T, van der Harst E, Hop WC, Jeekel J, et al. The use of mesh in acute hernia: frequency and outcome in 99 cases. Hernia. 2011;15(3):297-300.

2. Georgiev-Hristov T, Alvarez-Gallego M, Julia JB, Redondo MG, Veron A, Castell-Gomez JT. Necrotising fasciitis of the lower limb due to perforated inguinal 
hernia. Hernia. 2011;15(5):571-573.

3. Osorio JK, Guzman-Valdivia G. Ipsilateral Aymand's and Richter's hernia, complicated by necrosing fascitis. Hernia. 2006;10(5):443-446.

4. Sistla SC, Sankar G, Sistla S. Fatal necrotizing fasciitis following elective inguinal hernia repair. Hernia. 2011;15(1):75-77.

5. Schroeder JL, Steinke EE. Necrotizing fasciitis--the importance of early diagnosis and debridement. AORN J. 2005;82(6):1031-1040.

6. Wall DB, de Virgilio C, Black S, Klein SR. Objective criteria may assist in distinguishing necrotizing fasciitis from nonnecrotizing soft tissue infection. Am J Surg. 2000;179(1):17-21.

7. Wong CH, Khin LW, Heng KS, Tan KC, Low CO. The LRINEC (Laboratory Risk Indicator for Necrotizing Fasciitis) score: a tool for distinguishing necrotizing fasciitis from other soft tissue infections. Crit Care Med.
2004;32(7):1535-1541.

8. Andreasen TJ, Green SD, Childers BJ. Massive infectious soft-tissue injury: diagnosis and management of necrotizing fasciitis and purpura fulminans. Plast Reconstr Surg. 2001;107(4):1025-1035.

9. Miller AT, Byrn JC, Divino CM, Weber KJ. Eikenella corrodens causing necrotizing fasciitis after an elective inguinal hernia repair in an adult: a case report and literature review. Am Surg. 2007;73(9):876-879.

10. Roje Z, Matic D, Librenjak D, Dokuzovic S, Varvodic J. Necrotizing fasciitis: literature review of contemporary strategies for diagnosing and management with three case reports: torso, abdominal wall, upper and lower limbs. World J Emerg Surg. 2011;6(1):46.

11. Lakshmi V, Rani TS, Sharma S, Mohan VS, Sundaram C, Rao RR, Satyanarayana G. Zygomycotic necrotizing fasciitis caused by Apophysomyces elegans. J Clin Microbiol. 1993;31(5):1368-1369. 